only at a time, is better suited to measuring larger sizes.

Both instruments incorporate a monochromator, so that the fringe patterns can be observed in different radiations from a suitable source. The same technique of fringe observation is used, and the calculation of length is reduced to a simple procedure based on Benoit's method of exact fractions and the use of a Kösters wave-length slide-rule. Accurate measurement of gauge temperature is essential. Corrections are applied for departures of the gauge temperature and the ambient atmospheric conditions from the accepted standards, as well as for any dissimilarity of phase loss suffered by light reflected from the gauge and the base-plate surfaces.

Commonly used light-sources are the cadmium and the krypton discharge lamps of heated-cathode type manufactured by.the General Electric Co. When the krypton lamp is cooled in liquid air to reduce Doppler effect, lengths up to $30 \mathrm{~cm}$. (12 in.) are measured in the Kösters instrument to an accuracy of $\pm 0.025 \mu$ $\left(10^{-6}\right.$ in.), a figure which represents the average precision attained with both interferometers throughout their respective ranges of measurement.

Experimental work is proceeding in co-operation with the General Electric Co. on the development of discharge lamps for krypton-84, isolated by Dr. Koch as mentioned earlier, and for mercury-198 obtained from gold after irradiation with neutrons in a nuclear reactor. Several Fabry-Perot interferograms were exhibited which demonstrated the superiority of radiations from mercury -198 over those from naturally occurring cadmium and mercury. The fundamental importance of such sources in metrology and spectroscopy lies in the immediate prospect presented of establishing a wave-length of light as the ultimate length standard, and thus realizing an idea as old as the British Association itself.

H. BARRELL

${ }^{1}$ Littlefield, T. A., Proc. Roy. Soc., A, 187, 220 (1946).

${ }^{2}$ Bates, W. J., Proc. Phys. Soc., 59, 940 (1947).

${ }^{8}$ Barrell, H., Research, 1, 533 (1948).<smiles>CC(C)(C)C1CCCCC1</smiles>

\section{THE SCIENTIFIC DEPARTMENT OF THE NATIONAL GALLERY}

\section{By F. I. G. RAWLINS and A. E. A. WERNER}

$\mathrm{L}$ IKE many British ventures, the Scientific 1 Department of the National Gallery started in a small way. Even to-day it has no pretences to size, but it has probably grown up sufficiently to fulfil its purpose and to help, as experience shows it does, by advice over a wide field. In 1934 the board of trustees decided that a physics laboratory should be set up to collaborate with the art-historical staff in providing objective data concerning the methods used by the great masters, and to study picture structure and questions of atmospheric environment. At first there was little contact with problems of conservation. That, as the sequel shows, was to come a full decade later.

In early days it became manifest that the whole position would be strengthened if an advisory committee of distinguished men of science, interested in paintings, could be appointed to keep in touch with the laboratory and to act as a link between it and the board of trustees on one hand and outside institutions on the other. This was done (the trustees nominating the members), and the committee has rendered, and is rendering, a great service to the national collection. Meetings are held quarterly, when reports are received and discussed.

During the Second World War, with the pictures in exile at Manod Quarry, North Wales ${ }^{1}$, the task of the Scientific Department became one of dealing with the numerous difficulties, most of them entirely new, associated with underground storage on a considerable scale, and the erection and working of an airconditioning plant. That the task was accomplished may perhaps best be judged by the fact that up to 1939 the equivalent of eight months a year was spent in minor repairs to pictures (for example, laying blisters, closing cracks, adjusting stretchers, and so forth). The first year at Manod required about a fortnight's work : this progressively diminished until, in 1945 , the visit of the appropriate officer was purely formal : there was nothing to be done. A scientifically controlled environment had provided striking results. The return to London, however, provided a different story : the behaviour of the pictures, both panels and canvases, was alarming. There was an epidemic of flaking and blistering (due to the relatively rigorous climate of Trafalgar Square), the great frost of 1946-47 adding further to the Gallery's troubles. The need to harness all available scientific knowledge to help in the work of conservation of the collection has resulted in the establishment of a chemical laboratory (1948), and the extension of the physics section to include a wider choice of controls. Close association with the Department of Scientific and Industrial Research is a feature of the Department, and at all stages, before, during and after the War, much assistance has been most willingly given by the Ministry of Works.

\section{Physics Laboratory}

Partly by accident and partly by design, the physics section has tended to specialize in X-radiography and colorimetry. In addition, a fair amount of microscopy and physical optics is involved. All this is because it was soon seen that such processes represent a refined form of non-destructive testing applicable to basic needs and ad hoc problems alike. Broadly, in this laboratory we are concerned with the picture itself, not with its components, and thus, apart from work on 'models', we are more or less restricted to what radiations of various wave-lengths can tell us, both about condition and about picture-structure as such.

As might be expected, the prime essential is a knowledge of the anatomy of paintings : without this information, physical research is largely sterile. Support, ground, paint-film, surface-film, form a sequence of layers having close and complex relations with each other; moreover, the whole assemblage is in general strongly anisotropic, both minutely and in bulk. The support-usually wood or canvas-can be conceived as a biological substance of fairly normal character. Upon it are superposed the other layers, all more or less of the species 'paint', differing from each other in pigment-vehicle ratio and purpose more than in physical nature. These facts suggest forcibly a likeness to geological formations ; a typical stratified system with planes of weakness, slip, distortion, together with the presence of interfacial tensions, occluded gases and so on. In addition are forces of erosion and abrasion, not to mention intrusion and extrusion. Such a conformation invites investigation by petrological technique. That, in fact, is very 
largely the method in use. Wood itself has long been known to be approximately orthorhombic in symmetry, an observation of which use may be made in dealing with structural defects. Reactions to the intake and output of moisture from and to the atmospheric environment of a picture cause much trouble with panel paintings, and rational means of dealing with them depend in the last resort upon an appreciation of the elastic coefficients of an orthorhombic gel. Picture canvases usually shrink when dry and expand when wet (the opposite of the normal textile), on account of the hygroscopicity of the sizing overpowering the natural behaviour of the fibres.

From these considerations it will be seen that any information which physics can supply about structure, both general and local, is likely to be valuable both to conservators of paintings and to historians. The latter not infrequently desire objective evidence of certain types of build-up assumed to be characteristic of certain schools and masters. In such cases, of course, pictures in perfect condition and of undisputed authenticity are presented to the laboratory for examination. Concerning the means employed to achieve these ends, perhaps the most effective are $\mathrm{X}$-rays and infra-red radiation. The National Gallery is exceptionally well equipped in both these respects. Reduction of penetration in working with the former is essential if refined contrast between neighbouring areas of paint is to be obtained. Thus, for some years past soft rays from a tube working at $20 \mathrm{kV}$. have been used, whereas quite recently experiments have begun with a Machlett tube with beryllium window, permitting results to be obtained at $6 \mathrm{kV}$. Numerous initial difficulties are being experienced; nevertheless considerable promise is detected of ability to achieve selective differentiation hitherto unknown in such work. Other developments are contemplated.

The advantage of infra-red photography is that one is not presented with a picture composed of a number of superposed images, such as is normally the case with radiography. Thus, interpretation is apt to be simplified. Success depends, of course, upon the relative transmission and reflexion coefficients of the various layers: in favourable cases it is possible to reveal much of the condition of the paint-film behind a thick discoloured layer of varnish. Obviously this is a matter of importance to the restorer, especially in the early stages of his work. Ultra-violet light is also of importance in revealing the presence of repaint, and places where surface films have perished, in both instances by characteristic fluorescence. Viewed diagnostically, it is usually possible to obtain a very complete guide to the physical condition of a picture by means of X-rays, the ultra-violet and the infra-red.

Experience has shown that simple methods of colorimetry such as use of the Lovibond tintometer, and especially the Rothamsted improved instrument, can give much interesting information by comparison of a picture before and after cleaning. This method has been in use as a matter of routine for some years past, and the opportunity now afforded of being able to give results in international units seems likely to increase its usefulness many times. A kindred problem is that of gloss, especially in relation to the search for ideal surface coatings, which must possess acceptable optical properties, in addition to satisfying certain mechanical and chemical needs. In all these tasks the physical laboratory is busily engaged.

\section{Chemical Laboratory}

The decision of the board of trustees to set up a chemical laboratory was, to a certain extent, prompted by the recent controversy over the cleaning of pictures at the National Gallery ${ }^{2}$. The establishment of such a laboratory and the appointment of a research chemist were practical steps taken to increase the objective 'fact-finding' potential of the Scientific Department as a whole. The wisdom of this decision was endorsed by the report of the Weaver Committe ${ }^{3}$, which regarded it as a move in the right direction towards implementing certain of its recommendations. The chemical laboratory has been furnished and equipped in the most modern manner; in view of the many supply difficulties besetting a project of the type at the present time, a word of congratulation is due to the officers of the Ministry of Works responsible for the efficient manner in which the work was carried out, and the high quality of the workmanship.

The scope of work and the nature of the problems under investigation in the chemical laboratory vary widely. Hence, for the sake of convenience, they will be discussed under three separate headings, namely, (a) routine work, (b) investigation of ad hoc problems arising from the immediate demands of the Restoration Department, and (c) fundamental long-term research concerned chiefly with obtaining more precise information about many of the materials used by the old masters.

(a) The routine work involves, first of all, the supervision and testing of all chemicals-particularly organic solvents - used in the restoration studios, to ensure that they are up to the requisite degree of purity. Furthermore, there is the routine examination of paint specimens to determine the chemical nature of the pigments present. As well as using the classical mieroscopic tests, the Feigl 'spot-test' technique, using modern organic reagents for metals, is being developed with success; this technique is not only easier to carry out, but also the degree of sensitivity is in many cases greater. Information about the stratified structure of a painting is frequently of paramount importance to the restorer, and the technique of mounting cross-sections of paint specimens for microscopic examination is being tried out on a series of worthless canvases obtained for the purpose.

(b) In the past many of the techniques evolved as the result of empirical experimentation by restorers have been to a large extent dictated by the choice of that particular natural material the sum of the properties of which was most suitable for the job in hand. It inevitably followed that certain methods of treatment necessitated a compromise and consequent departure from the ideal method, which must be visualized as involving the absolute minimum of risk to the painting undergoing treatment. In an attempt to remedy this state of affairs, it is appropriate to inquire to what extent these traditional materials may with advantage be replaced by newer materials, particularly those of the synthetic high-polymer type, thus evolving a simpler and probably safer method of treatment. A close analogy is supplied by natural rubber which, on account of its unusual combination of properties, was used for many purposes for which it was not ideally suited; it has now been superseded in many instances by synthetic elastomers.

In illustration of this principle, the following ad hoc problems, which are at the moment under active investigation, may be considered. The traditional 